\title{
Persistent features from a palaeo-landscape: the ancient tracks of the Maltese Islands
}

\author{
KAREL J. HUGHES \\ School of Life Sciences, Roehampton Institute London, London SW15 3SN \\ E-mail: K.Hughes@roehampton.ac.uk
}

This paper was accepted for publication in March 1998

I'd like someone to explain, if they can, what I observe.

Translated from Houel, 1787: 101

\begin{abstract}
The ancient Maltese tracks or 'cart-ruts' remain an enigma; they have not been satisfactorily explained. This subject is reviewed as a precursor to a research agenda focusing on a geoarchaeological analysis of the tracks within a GIS reconstruction of the Maltese palaeo-landscape. Conjectures on the origin, function and date of these persistent and intriguing anthropogenic features are discussed in the context of the prehistoric archaeology and natural resource geography of the islands. It is argued that the track network represents a key input into a coherent reconstruction of an ancient and unique landscape.
\end{abstract}

KEY WORDS: Malta, Gozo, Maltese Islands, geoarchaeology, archaeology, cart-ruts, prehistory, GIS, landscape reconstruction, natural resources, ancient transport system, Mediterranean.

$\mathrm{I}$

SLAND LANDSCAPES, subject to contemporary anthropogenic transformations, assume a conformity which is an expression of a global rather than any local culture. In contrast, the physical isolation and insularity of island societies in the past fostered the development of distinctive cultures with qualitatively differing, and sometimes unique, perceptions of the natural world which they expressed in the landscape. Despite the temporality or essential dynamism of landscape, places and features of cultural significance persist as powerful expressions of the way past societies perceived, shaped and interacted with their topography and resources. The Maltese landscape exemplifies this duality: amongst the remnants of a remarkable archaeological heritage, a residual network of tracks coexists as a persistent memory of some deliberate human activity which has endured centuries of both natural and human-induced change. These tracks, which have eluded satisfactory explanation, may represent a key input to a coherent reconstruction of an ancient and unique landscape.

The Maltese Islands are distinctive owing to their:

- relative geographical isolation;

- limited size;

- centrality in the Mediterranean Basin;

- landscapes dramatically transformed through human activity; and
- a prehistoric heritage described as extraordinary, unique and without parallel in the Mediterranean region, or elsewhere in the world (Childe, 1957; Renfrew, 1973; Evans, 1959, 1971; Trump, 1981; Brea, 1960; Zammit, 1930a; Cherry, 1990; Stoddart et al., 1993).

It is something of a paradox that, despite a limited resource base, the islands of Malta and Gozo have regularly sustained unusually high population densities (Quintin, 1536; Adams, 1870; Renfrew, 1973; Cassar, 1997) and a rich cultural heritage which is everywhere reflected in the created and transformed landscape (Bowen-Jones et al., 1961; Hunt, 1996; Farrugia and Briguglio, 1996; Boisgelin, 1805; Schrembi, 1997; Jones and Hunt, 1994).

This paper is both a literature review and a precursor to a research agenda involving a contextual and spatial analysis of the Maltese tracks, in conjunction with a reconstruction of the prehistoric palaeolandscape. The spatial, temporal and human dimensions of these ancient tracks make them a suitable candidate for a GIS investigation; they are essentially geographical, an enduring expression of human ingenuity and achievement, a practical response to some strategic decision, a persistent but enigmatic reminder of the way a society, at an unknown point in time, responded to their particular needs. 


\section{Background}

If the ancient tracks are the result of deliberate human action, then this action followed some cultural appraisal of the islands' material attributes, or stock resources and it is, therefore, appropriate to establish the physical foundations for this dynamic.

The Maltese archipelago, which includes Malta, Gozo and Comino, lies centrally in the Mediterranean Basin some 250 kilometres from mainland Europe, 290 kilometres from North Africa and 96 kilometres from the island of Sicily (Fig. 1). The islands are small: Malta, the largest has a surface area of only 245.7 square kilometres, Gozo 67.1 square kilometres and Comino 2.8 square kilometres. Boundary configurations, topography and their island status are the outcome of tectonic activity associated with active plate convergence (Reuther, 1984; Illies, 1981), coupled with post-Quaternary sea-level changes. Like much of the Mediterranean, these islands are dominated by limestone; unlike neighbouring islands (Sicily and Pantelleria), igneous outcrops are entirely absent (Zammit-Maempel, 1977; Bosence, 1990; Pedley et al., 1976).

The islands are dominated by Mid-Tertiary, Oligo-Miocene carbonate rocks originating as sediments which accumulated in a shallow shelf environment. The relatively simple succession of limestone strata, interstratified by a calcareous clay facies, are generally only moderately flexured but are characterized by extensive faulting (Reuther, 1984). The juxtaposition of strata of varying composition and thickness, displaced by Miocene and post-Miocene faulting, gives rise to a distinctive topography (Alexander, 1988). The more competent beds of Coralline Limestone generally form upland plateau and ridges (horsts) while the less competent Globigerina Limestone, extensive in Gozo and eastern Malta, is associated with a more undulating topography; the limited outcrops of Blue Clay form highly distinctive, unstable slopes in western Malta and Gozo (Bosence, 1990; Pedley et al., 1976; Alexander, 1988). Surficial deposits of PlioQuaternary age are limited to a few locations particularly around the coast, in fissure fillings and caves (Cooke, 1896; Trechmann, 1938; Alexander, 1988; Hunt, 1997). The overall geometry of Malta has been determined by tilting and subsidence giving rise to a generally submerged northern boundary associated with shallow bays and coastal lowlands, in contrast to the pronounced elevation of the southern boundary characterized by dramatic, fault-controlled coastal cliffs.

The structural geology of the Maltese Islands is controlled by two distinct, superimposed fault systems which determine the topography (Illies, 1981; Pedley et al., 1976). The uplift of the marine sediments and their subsequent warping, tilting and fracturing is associated with the position of the islands close to the leading edge of the African plate. Different tectonic stress regimes, accompanying crustal extensional processes, have produced a conjugate fault pattern with major, first generation faults generally striking east-north-east, responsible for the classic horst and graben topography, and a later system trending north-west; the islands are considered to be still experiencing neotectonic activity (Illies, 1980; Reuther, 1984) although the frequency and magnitude of earthquake activity is low (Alexander, 1988; Ventura and Galea, 1995; Hyde, 1955; Rizzo, 1932; Zammit-Maempel, 1977).

Karstic phenomena, associated with the islands' structural and lithological inheritance, are common and sometimes remarkable. These include extensive small-scale lapies or kärren solution features, terrestrial and submerged cave systems, and numerous, large-scale solution subsidence structures (Pedley, 1974; Pedley et al., 1976; Zammit-Maempel, 1977; Hunt, 1996; Alexander, 1988; Guicher and Paskoff, 1975; Paskoff and Sanlaville, 1978; Rizzo, 1932; Vossmerbäumer, 1972).

Geomorphological processes, intensified and accelerated by the juxtaposition of competent and incompetent sedimentary strata, Mediterranean climatic conditions, and most probably, superficial tectonic activity, are responsible for slope collapse. High magnitude mass wastage has been a persistent process in the landscape (Hobbs, 1914; Alexander, 1988; Paskoff and Sanlaville, 1978), testifying to the continuing instability of the islands and demonstrated by the ubiquitous masses of relict and contemporary block debris which clothe the steep slopes of the interior and the coastal cliffs.

In common with other Mediterranean islands (Kraft et al., 1977; Van Andel, 1989; Lambeck, 1996), coastal bathymetry (Martineau, 1965) indicates that the surface area of each island has been considerably reduced by a transgressing sea. During periods of minimum sea level in the recent geological past, the islands were most probably connected to Sicily as the depth of the intervening sea is generally shallow, less than 90 metres and never deeper than around 200 metres (Vossmerbäumer, 1972; Alexander, 1988). Remnants of raised beaches, submerged marine platforms and karstic phenomena indicate complex tectonic and eustatic changes which continue to affect the islands.

The Mediterranean climate of the islands is characterized by a low average annual rainfall (c.530 $\mathrm{mm})$ concentrated in a few Winter months, and a hot dry Summer with average annual temperatures around $19^{\circ} \mathrm{C}$ (Chetcuti et al., 1992; Schembri, 1994). However, this broad-brush description fails to convey the uncertainty and dynamism of the present climate (Mayes, 1995). In company with the rest of the Mediterranean, the islands have experienced marked fluctuations in climatic regime during the Holocene 


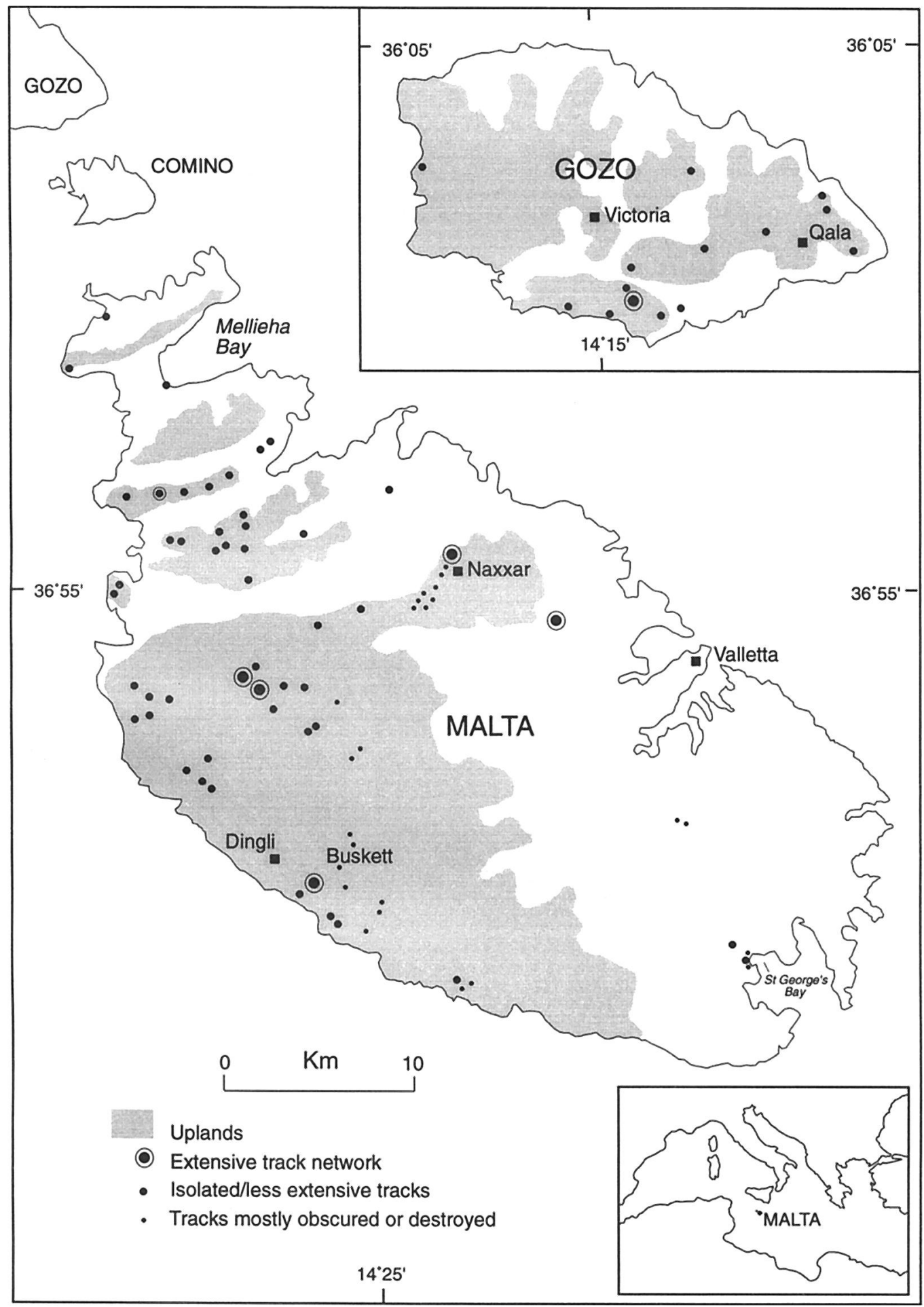

Fig. 1. Distribution of isolated tracks and track networks in Malta and Gozo 
with periods of persistent drought and wetter, cooler conditions (Lamb, 1982; Weiss, 1982; Neumann, 1993).

Surface water is generally transient in these islands; springs, at the Blue Clay - Upper Coralline Limestone junction (Newbery, 1968) are associated with semipermanent pools; the valleys, or widiens of Pleistocene origin (Park, 1977) remain dry for much of the year but experience, irregular, flash-flooding after storms Mitchell and Dewdney, 1961; Chetcuti et al., 1992; Anderson, 1997). The permeable limestones act as aquifers above (perched) and below the Blue Clay (Newbery, 1968; Morris, 1952; Chetcuti et al., 1992; Zammit-Maempel, 1977). While caves are numerous, only the Ghar Harq Hamiem cave in south-east Malta is known to contain freshwater at the present time (Schembri, 1994). Although it is probable that the geology of the islands would have precluded the existence of surface water in the prehistoric period, the effects of climate change, sea-level changes and possibly geological perturbations are unknown.

The soils of the Maltese Islands are naturally low in humus, generally highly calcareous and often thin (immature xerorendzinas and carbonate raw soils); the relic terra rosa soils are also characterized by a high ferruginous composition giving rise to their distinctive red colouration (Schembri, 1994; Lang, 1961). Much of the original soil was largely derived from aeolian silt and thus highly vulnerable to erosion (Hunt, 1997). However distinctive the geological and climatic controls have been, the existing soils are complex and difficult to categorize owing to centuries of intense human activity. Soil thickness, fertility, water-storage properties, and actual soil distribution are the result of human strategies to improve the productivity of a limited resource; terracing of slopes, including those on precariously steep cliffs, represents a persistent, centuries-old anthropogenic feature of the landscape (Adams, 1870; Boisgelin, 1805; Bowen Jones et al., 1961; Blouet, 1967; Jones and Hunt, 1994).There is a persistent local belief that soils were imported in the past, possibly by the Knights; there is no conclusive evidence of this (Zammit-Maempel, 1977: 35).

The biodiversity of small islands is generally limited owing to the low number of habitats and the decreased opportunities for colonization; more isolated islands would be expected to be more ecologically impoverished and unstable (MacArthur and Wilson, 1967). In a biogeographical context, the Maltese Islands with their limited surface area, physical isolation, dominance of calcareous bedrock and semi-arid climate, have a limited range of available resources. In the earliest published description of Malta, the island was described as being 'practically wholly rocky and rough' with 'adverse natural features' (Quintin, 1536: 19 and 37). By the nineteenth century the island was described as: bare, weather-beaten, rocky, and sterile to a degree, no woods, and scarcely a tree to be seen anywhere.

Adams, 1870: 75

More recently the natural environment has been described as 'impoverished' and in a 'precarious state' (Schembri, 1997: 121-3). Prior to human colonization and intense exploitation, extensive woodland (Mediterranean Sclerophyll Forest type) may have covered the islands characterized by Holm Oak (Quercus ilex) and Aleppo Pine (Pinus halepensis) but this is virtually extinct (Lanfranco, 1996; Schembri, 1994; Bowen Jones et al., 1961). Maquis, garrigue, steppic grassland, planted woodlands, caves, coastal marshes, shorelines and cliffs, provide habitats for a relatively diverse array of plants and animals including important endemic species of cultural and scientific significance (Schembri, 1994); one such species (the so-called 'Malta Fungus', in fact a parasitic vascular plant Cynomorium coccineum) was particularly renowned, and traded in the seventeenth century for its medicinal benefits (Lanfranco, 196la; Boisgelin, 1805; Houel, 1787).

\section{Geoarchaeology}

The reconstruction of past landscapes has traditionally been part of the geographical disciplines, enhanced and extended in the last decade through the use of digital terrain modelling, remote sensing and Geographical Information Systems. The diffusion of disciplinary boundaries, and the recognition of the need for a more spatial and synergistic approach in archaeology, has led to a rapid growth in geoarchaeology, visualization and GIS (Llobera, 1996; Lock and Stancic, 1995; Zubrow, 1994; Allen et al., 1990). The joint Anglo-Maltese Archaeology Project based on Gozo is an example of the use of an interdisciplinary team currently involved in using palaeoenvironmental data to reconstruct and visualize the Gozitan prehistoric landscape (Burgess, 1997).

Prior to this initiative, attention in the Maltese Islands had focused almost exclusively on the monumental architecture (Mayr, 1909; Vance, 1842; Anati and Anati, 1988; Anati, 1995; Ugolini, 1934; Houel, 1787; Ashby et al., 1913; Caruana, 1886; Trump, 1962, 1963, 1966, 1977, 1981; Zammit, 1930a and b; Evans, 1953, 1959, 1971; Brea, 1960) and the numerous burial sites (Tagliaferro, 1911; Baldacchino and Evans, 1954; Zammit, 1928, 1935; Caruana, 1888; Whitehouse, 1972). Relative to other populated Mediterranean islands, Malta's geographical isolation, limited size and singular prehistoric culture has attracted attention in the context of:

- initial colonization theories (Cherry, 1981, 1990; Patton, 1996);

- the correlation between monument building and the evolution of hierarchical island societies (Renfrew, 1973; Bonanno et al., 1990); and 
- the gestation of cults and mortuary rituals in island societies (Stoddart et al., 1993; Malone et al., 1993; Skeates, 1996; Malone et al., 1995).

Despite the renewed interdisciplinary academic interest in Maltese prehistory, the spatial and chronological dimensions of the ancient track network have not been addressed.

\section{The ancient tracks, or Maltese 'cart-ruts'}

The Maltese tracks have inspired a great deal of speculation but have largely been marginalized in the archaeological and geographical literature; they have never been the subject of an island-wide scientific investigation. This may be explained by:

1 the absence of dateable artefacts;

2 their very uniqueness which defies easy classification or ownership either in the archaeological or geographical domain; and

3 paradoxically because they may have been perceived as commonplace owing to their 'familiarity' and attribution to carts.

Only Dawkins (1918: 87) considered the 'cart-ruts' entirely natural features and 'of no archaeological significance'.

Nevertheless, since the seventeenth century the tracks have excited curiosity and comment (Abela, 1647; Houel, 1787; Boisgelin, 1805). Houel (1787) and Boisgelin (1805) considered the tracks remarkable and, even while acknowledging their similarity to conventional cart-ruts, were hugely perplexed by their origin, their function and their wide distribution. They were described as the:

vestiges of wheels, that have cut into the rock and may be traced to the sea.

Boisgelin, 1805: 49

While they were similar to the ruts left by carts in soft ground, these were apparently 'frozen' in the rock which previously had been damp and soft:

Ces Ornières semblent l'ouvrage d'une voiture très-chargée, à deux roues, qui en passant dans un terrain attendri par l'humidité, auroient enfoncé considerablement laissant ce terrain comme s'il avoit été gelé aussi-tot.

Houel, 1787: 100

Rock-incised rutted tracks have been recognized in Sicily, Sardinia, Italy and southern France (Houel, 1787; Trump, 1993; Bonanno, 1994; Parker and Rubinstein, 1984; Pike, 1963). These tracks do not appear to have stimulated as much interest, possibly because they are relatively few in number, of generally limited extent, and often confined to mainly classical sites where their function was more obviously associated with quarrying for building stone or trade.
There is little evidential basis for assuming these tracks have the same origin, purpose or chronology as those in the Maltese Islands. Their morphological characteristics and spatial patterns have not been thoroughly investigated, giving no real opportunity for reliable comparison. However, Pike (1963) did measure a number of 'authentic' Roman, Greek and modern rutted tracks at different localities in the western Mediterranean and found none analogous to those in Malta and Gozo. Evans (1971: 202), like Houel (1787), observed that the tracks were 'quite different from modern cart ruts'.

Spatial characteristics: patterns and behaviour of tracks The tracks can be observed in both Malta and Gozo, wherever limestone is exposed (Plate I, Fig. 1). Archival texts suggest they were once more extensive (Houel, 1787; Adams, 1870); this is confirmed in some cases by early aerial photographs (Zammit, 1928; Ventura and Tanti, 1994) and maps (Gracie, 1954; Parker and Rubinstein, 1984); none have been identified on Comino. As the general location map indicates (Fig. 1), discontinuous networks and isolated remnants of tracks are more frequently observed in southern and western Malta where the extensive uplands are typified by expanses of exposed Coralline Limestone. They are found incised into Globigerina Limestone but on a very much more limited scale as relatively little is exposed. Extensive quarrying, which has increased by an estimated 200 to 300 per cent since 1983 (Balm, 1996: 83), has been responsible for obliterating some recorded tracks and represents a serious threat to the remaining sites (Ventura and Tanti, 1994).

A fundamental prerequisite in a geoarchaeological investigation is to identify and characterize the spatial and chronological dimensions of the phenomena under investigation. The British archaeologist, David Trump, while engaged in fieldwork, and as Curator of Archaeology at the National Museum of Malta (1958 to 1963), has become very familiar with the tracks and has been responsible for systematically locating and recording sites (Trump, 1993). However, the overall pattern of the network has not been mapped or analysed although this is in progress (Hughes: in prep.). Useful contributions to this mapping task have been made at a local scale (Gracie, 1954; Parker and Rubinstein, 1984), but only one area has been mapped in detail (Ventura and Tanti, 1994). Simple sketches (Adams, 1870) and aerial photographs (Zammit, 1928; Trump, 1966) also provide extremely valuable archival information. Descriptive accounts by early writers, while sometimes frustratingly vague in terms of location, provide useful insights into the distribution of tracks prior to large-scale changes in the landscape; a marked degree of consistency has been noted in these impressionistic accounts (Abela, 1647; Houel, 1787; Boisgelin, 1805). 


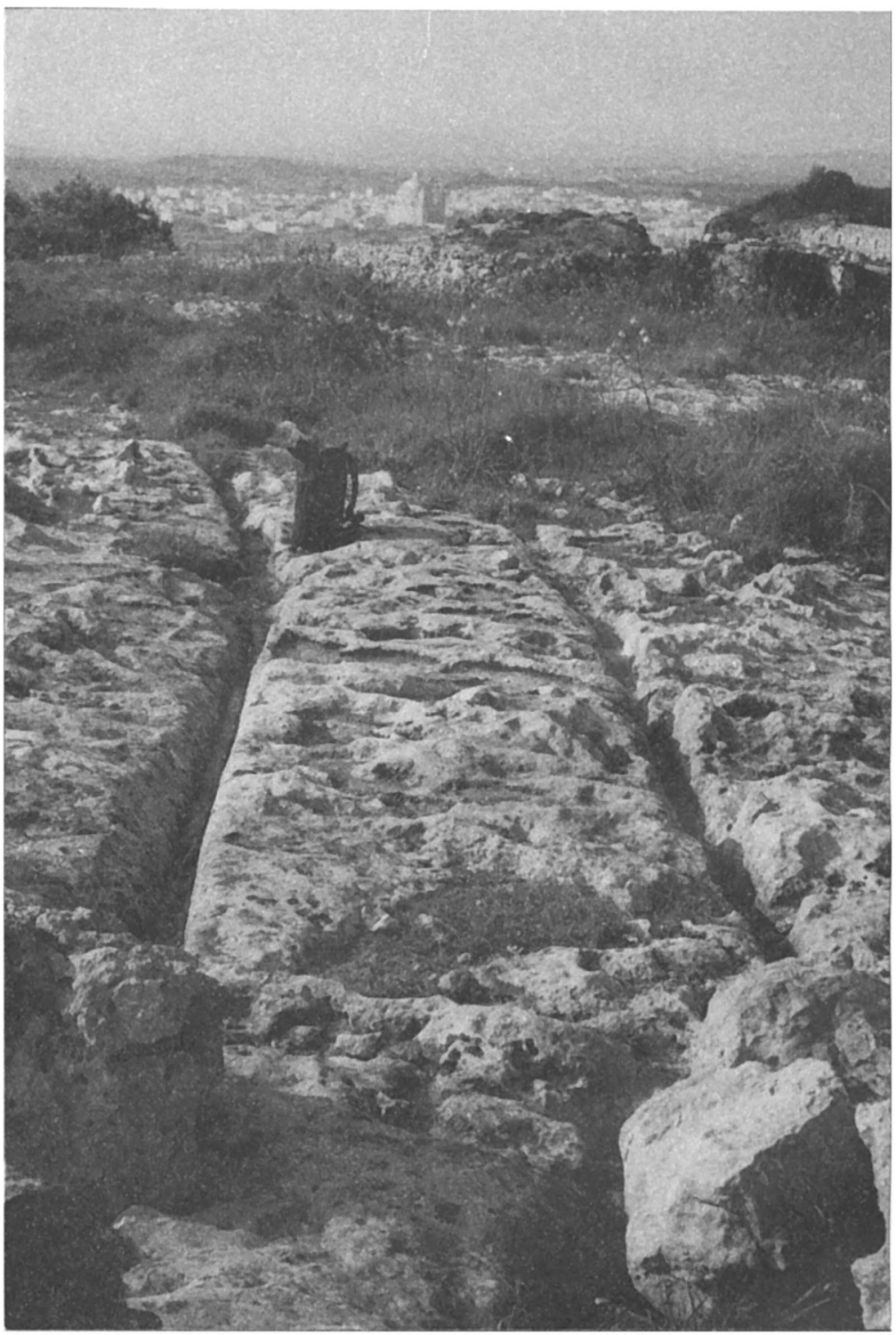

PLATE I Incised tracks near Bingemma (439736) north-west of Rabat. Part of an extensive system of tracks incised into the Coralline Limestone on the southern uplands

Trump (1993: 32) recognized a 'common pattern' to the tracks, suggesting that their distribution was typified by routes that crossed the ridges from one 'cultivated valley' to the next, vanishing 'beneath the fields' and often following topographically convenient routes, much the same as modern roads. However, this pattern, while assumed by the Maltese archaeologist T. Zammit (1928), was not recognized by Gracie (1954), who made the first serious attempt to classify, quantify and analyse local patterns. Other investigators noted, somewhat ambiguously, that the tracks had a tendency to 'run up or down a gradual slope' and, while acknowledging that some tracks did coincide with the route of modern roads, thought that the majority were located in areas associated with ancient routeways (Parker and Rubinstein, 1984: 9).

Gracie (1954) investigated 50 lengths of tracks at 
two localities in western Malta, noting their distribution in relation to topography. The dominant pattern revealed was not from valley to valley across the ridges as the majority of tracks either followed the contour along the ridges $(24 \%)$, or led directly out to promontories $(22 \%)$; only six per cent led directly from the valley towards ridge summits, 12 per cent led up and over ridges, 12 per cent traversed valley heads, eight per cent ran parallel to cliff edges, four per cent linked with cave dwellings and four per cent headed across the low-lying plain. Early observers (Houel, 1787; Boisgelin, 1805) noted that tracks appeared to head towards the sea but Gracie mapped only six per cent in this direction. The dominance of contour-following tracks is indicated in an excellent map of the Naxxar Gap complex published by Ventura and Tanti (1994).

The distribution of tracks at or near the coastline, and their perceived anomalous behaviour, has been the source of much speculation. Tracks apparently 'disappearing' over the cliff in southern Malta are relatively common (Parker and Rubinstein, 1984; Adams, 1870; Boisgelin, 1805; Trump, 1993). However, Zammit observed that tracks frequently followed the cliff line and at one site noted a track traceable on a detached block in 'a direction nearly parallel to the cliff' (Zammit, 1928: 21); similar routes are confirmed by Gracie's (1954: 94) map. Submerged tracks have been observed (Houel, 1787; Adams, 1870; Fenton, 1918; Ward-Perkins, 1942; Boisgelin, 1805) but the only remaining evidence can be found at St George's and Mellieha Bays in Malta (Trump, 1993). Adams (1870) sketched a pair of tracks running some distance parallel to the coastline, disappearing and reappearing on opposite sides of the St George's Bay. Gracie (1954) was unable to confirm the continuity of tracks across the bay (possibly because of road construction), but was able to detect the still-visible pair running out into the bay under a metre or so of water.

At a local scale, the specific organization of the tracks has been noted; branching, parallel and intersecting patterns have been recognized or inferred. Houel (1787: 100) observed that some parallel tracks were interrupted or crossed by circular routes; at a number of localities, tracks appear to diverge and converge after a short distance giving rise to a distinct 'loop' pattern traceable in the field and from aerial photographs (Parker and Rubinstein, 1984; Zammit, 1928; Trump, 1993: 121); in some cases the 'loops' have been mapped (Gracie, 1954: 94; Ventura and Tanti, 1994: 239) and designated as passing places (Zammit, 1928: 20) although this idea was disputed by Gracie (1954: 95). Recent fieldwork data from a track complex in southern Malta (Buskett-Dingli area) indicate that the spatial organization of tracks has similarities with those mapped by Ventura and Tanti (1984) at Naxxar (Hughes, in prep.).
Ventura and Tanti (1994) having mapped an entire local network (covering about 5 hectares) noted in detail the possible chronological relationship between superimposed and adjacent tracks; the first comprehensive morphological data set is published with their paper.

Track morphology Probably one of the most intriguing aspects of the incised ruts forming the tracks is their very distinctive morphology. The degree of rut incision varies considerable, from mere traces to over 50 centimetres (maximum depth recorded is $67.5 \mathrm{~cm}$ : Gracie, 1954). Ventura and Tanti's data demonstrate, that at least at one site, the average depth of different ruts, other than trace features, varied from two to 26 centimetres with the deepest rut measured at 55 centimetres; paired ruts varied by up to 18 centimetres (1994: 238). The variability in rut depth, both along-rut and between paired ruts, was confirmed by preliminary fieldwork data from the Buskett-Dingli area: for example, along-rut depths varied from 14 to 35 centimetres over a distance of 210 metres, while paired ruts (across-track) differed by up to 15 centimetres. The deepest rut measured was 59 centimetres, the shallowest six centimetres. Cross-track asymmetry has been attributed to displaced or tilted loads as the vehicle traversed sloping terrain (Zammit, 1928: 18; Gracie, 1954: 95); variation in along-rut depths may be attributable to local lithological changes.

The ruts show a persistent non-rectangular form. They vary in cross-sectional morphology but are generally described as wider at the top, narrowing to a V-shaped or rounded U-shaped profile, exhibiting a more flattish shape only where duplication has occurred (Lewis, 1977; Zammit, 1928: 18; Gracie, 1954: 95; Pike, 1963; Ventura and Tanti, 1994: 231). This contrasts with less ancient cart-tracks, often associated with quarrying, which generally have wider, shallower rectangular rut profiles Ventura and Tanti, 1994: 231; Gracie, 1954: 97; Pike, 1963: 10; Trump, 1993: 33; Zammit, 1928: 19). The data published in Ventura and Tanti's paper (1994: 238) indicate that the upper width of the tracks in their study area averaged from 15 to 31 centimetres (narrowest: $8 \mathrm{~cm}$; maximum: $53 \mathrm{~cm}$ ); width at the base of the tracks averaged between six and 14 centimetres (narrowest: $4 \mathrm{~cm}$, maximum: $27 \mathrm{~cm}$ ). In the BuskettDingli area, the average upper width and base dimensions of tracks were considerably greater indicating marked differences in incision and lateral wear attributable to more intense and/or frequent activity in this area; a more extensive survey is required before a full comparative analysis can be achieved.

The gauge characteristics of the tracks vary but average around 1.40 metres. At Naxxar, gauge varied from a minimum of 130 centimetres to a maximum of 152 centimetres (Ventura and Tanti, 1994); 
at Buskett-Dingli, equivalent measurements were recorded at 137 centimetres and 160 centimetres (Hughes, in prep.). Zammit (1928: 18) noted that the gauge was 'nearly always 4 feet 6 inches' $(137 \mathrm{~cm})$, Gracie (1954: 91) observed that the paired ruts were '52 inches to 58 inches apart' (i.e. $132 \mathrm{~cm}$ to $147 \mathrm{~cm}$ ), and Trump mentions an average gauge of 130 centimetres (Trump, 1993: 34). Early prehistoric wheeled carts in Europe had gauges varying from 130 to 175 centimetres (Piggott, 1983: 57-59). By the Bronze Age, wheel gauges appeared to have stabilized between 140 and 145 centimetres which was attributed to 'a mature and established tradition in technology and workshop practice' which was 'perpetuated throughout European antiquity' (Piggott, 1983: 68). The persistence of this gauge throughout historic times is demonstrated by the railway network in the UK a 'Standard Gauge' of 143.5 centimetres was adopted in 1845 because of the original need to accommodate the wheels of nineteenth-century carts and wagons (Cope, 1993: 18). The gauge 'coincidence' has been cited or implied in support of arguments attributing the ancient tracks to wheeled vehicles (Fenton, 1918; Zammit, 1928). Pike found that the gauge of a track, attributed to the Greeks, in southern France (near Fos-sur-Mer) measured a consistent 140 centimetres over a relatively long distance; track gauges in Malta varied considerably over very short distances (Pike, 1963: 13). Others have also noted that gauge variability is typical of the ancient Maltese tracks (Gracie, 1954; Ventura and Tanti, 1994).

Vehicle technology: wheels, sledges or slide-cars? The question of the vehicle design has been addressed in the literature rather more assiduously than the actual pattern. The dimensions and general morphology of the paired tracks, appearing familiar to observers in the seventeenth to early twentieth century, made it almost inevitable that they would be attributed to the passage of wheeled carts (Boisgelin, 1805; Fenton, 1918; Zammit, 1928; Fox, 1931; Evans, 1934); more recently others found 'it almost impossible to entertain any alternative explanation' (Parker and Rubinstein, 1984: 15) but Blouet (1967), while aware that the tracks appeared to look like cart-ruts, opinionated that they were 'almost certainly not' of this origin; Houel (1787: 100) remained mystified. Fenton, observing early twentieth century largewheeled carts in Malta, concluded that the tracks were made by 'high strong wheels' (Fenton, 1918: 67), a proposition more recently advanced by Trump attributed the tracks to 'loosely fitted heavy carts' (Trump, 1993: 34).

Others are convinced that wheeled vehicles could not have been involved (Gracie, 1954; Evans, 1959, 1971; Blouet, 1967; Lewis, 1977; Ventura and Tanti, 1994). Houel observed that eighteenth-century carts did not leave such traces (Houel, 1787: 101). Gracie (1954) argued persuasively that the tracks were very unlikely to be the result of wheeled carts due to their shape and depth, and what he considered were relatively sharp changes in track direction. He concluded that five-feet diameter wheels would be needed to prevent the axle becoming stuck where one or both ruts were particularly deep. He was convinced that they were the result of a slide-car (or travois) device and disagreed with Zammit's (1928: 18) proposition that high-wheeled vehicles were used. His theory was tested experimentally in 1955 in preparation for a BBC Television film about Maltese prehistory. A set of cart wheels, a sledge and a slide-car were drawn along tracks at Naxxar Gap; only the slide-car moved easily along the tracks. Gracie's slide-car theory was supported by Evans (1959: 190; 1971: 203).

Lewis also experimented successfully with a fullyloaded travois-type vehicle with wooden shafts clad with stone runners which 'glided smoothly over the stone surface' of the tracks (Lewis, 1977: 63). He also makes reference to 'peculiarly shaped stone(s)' found at an unnamed Bronze Age settlement site which seemed to him to have been designed for this purpose (Lewis, 1977: 62); there appears to be no archaeological reference or confirmation of such artefacts. Wheels have been rejected in favour of a slide-car by Ventura and Tanti (1994) following analysis of their detailed measurements of track morphology at Naxxar, but their contention is tentative and they emphasize the need for more research. A sledge design has been rejected because of the apparent sudden changes in direction of the tracks, their depth and irregular gradient (Trump, 1993); experimental use of a sledge was unsuccessful (Evans, 1971). A maverick suggestion came from E.M.P. Evans (1934) who proposed an unusual system of solid, rock-cut rollers.

Strong consensus is absent: there is support for a wheeled vehicle despite the results of the field experiments. Interestingly, Piggott, probably one of the most authoritative writers on ancient wheeled transport, acknowledges the 'well-known' tracks which appear to have 'no counterparts in the Mediterranean or elsewhere', but does not attempt to speculate on their origin, only confirming that practical experiments had jettisoned the notion of wheeled and sledge transport (Piggott, 1983: 38).

Traction: pushed or pulled; man, woman or beast? Traction has been described as remaining 'the outstanding problem' (Trump, 1993: 34); no evidence has been identified that gives any clue as to how the vehicle might have been moved, a mystery which engaged the minds of early observers (Houel, 1787: 101). The high density of tracks in some localities, and the general roughness of the terrain would have precluded animal traction. This has been 'explained' by 
the suggestion of a soil cover; the irregularities of the rock surface and abandoned tracks filled and covered with soil, would effect a relatively smooth surface for the passage of hooves or human feet (Fenton, 1918; Gracie, 1954).

Animal traction has been suggested (Fenton, 1918); this has been rejected as there appears to be no evidence of wear concomitant with the amount of traffic evidently responsible for the ruts themselves (Trump, 1993). People-traction, including slave labour, has seemed more plausible (Parker and Rubinstein, 1984; Fenton, 1918; Lewis, 1977; Zammit, 1928). Human assistance may be indicated by grip marks, observed at a number of sites, cut in the rock immediately adjacent to tracks (Parker and Rubinstein, 1984; Ventura and Tanti, 1994). Some observers considered the rock smoothed by 'countless feet' (Parker and Rubinstein, 1984: 16); others only recognized irregular, rough terrain (Zammit, 1928; Trump, 1993).

Incision: worn or tooled? The tracks have endured as persistent features in the landscape for possibly thousands of years because they are incised so emphatically in the solid limestone (Plate I). This has given rise to considerable speculation on the specific processes involved in their creation. The consensus favours wear through frictional erosion. Zammit, however, was convinced that they had been actually cut by design and 'traced by tools to start the track', and that it was certainly possible that something 'sharper and steadier than wheels must have produced them' (Zammit, 1918: 252); he later modified this, suggesting that only some were cut and others were worn (Zammit, 1928: 20). Evans (1934: 340) also maintained that the ruts were 'marked out and cut by hand'. Trump still speculates on the possibility of deliberate action having identified a pair of ruts on Xemxija Hill which 'appear to have been pecked' (Trump, 1993: 33 and pers. comm., 1997). Pike (1963) found no evidence of tool-marks in Malta and noted that only the ruts examined at Agrigento in Sicily showed evidence of chisel marks.

Attribution purely to frictional erosion is not surprising as morphologically similar results can be expected, and have been observed, from wheels moving across incompetent material such as damp clay. However, the promulgation of this argument in the literature has usually been dependent on the rock being covered by soil; no argument has been made which entails wear directly on the naturally-exposed rock. The underlying logic of the argument is that as limestone, once exposed, develops a patina or relatively harder 'crust' (Gracie, 1954: 96) or 'tufa mantle' (Zammit-Maempel, 1977: 28), the surface would not be readily breached by any primitive vehicle. However, vehicles moving across soil-covered limestone in a more humid environment would quickly erode through the soil leaving superimposed ruts in the underlying 'soft' rock (Gracie, 1954).

Fenton (1918) concluded that the duplication of tracks, a common feature in some localities, could only be explained by soil obscuring existing tracks which were then superimposed by later tracks following similar but not identical routes. This explanation was reiterated by Gracie who suggested that the: 'land was soil covered and only one track was visible at any one time' (Gracie, 1954: 98). This in part resolved, at least in Gracie's mind, the complex pattern of track duplication and superimposition but exposes inconsistencies in his argument. He inferred that following heavy rain, thick, eroded slope deposits obscured earlier ruts (Gracie, 1954: 96). He mapped the majority of tracks on the slopes and summits of ridges, the very sites where rapid erosion rather than deposition would be likely to occur.

Trump (1993: 18) suggested initially that the ruts were incised into rock which had 'all but lost' its original soil cover but remained perplexed by tracks which became progressively fainter. As he could find no evidence of rock erosion, he could only conclude that this was evidence of a 'former soil cover, since swept away' (Trump, 1993: 32). Ruts are interrupted occasionally by solution hollows which has reinforced his opinion that the tracks must have originated in soil otherwise such features would surely have been avoided (Trump, 1997: pers. comm.).

Parker and Rubinstein acknowledged that it would be unlikely that the tracks were worn in 'hardened' long-exposed rock and that the wheels would not have survived without an impossible amount of maintenance. To circumvent this problem, and having noted (although it is unclear whether the authors had visited the sites) that in quarries elsewhere in the Mediterranean, 'ruts were made in rock from which the overlying material had been removed' they proposed this explanation for the Maltese tracks, implying that tracks became 'fixed' as a result of the development of a 'tufa mantle' (Parker and Rubinstein, 1984: 19). This argument, therefore, presupposes that in every area where incised tracks are located the original rock surface was removed by human action immediately prior to vehicular movement and that 'hardening' of the new rock surface happened rapidly.

Irrespective of vehicle design, the materials used in their construction is clearly pertinent to this discussion. Observing their incision and roughness, some authors have been convinced that iron and wood must have been used in the construction, with sturdy, iron-rimmed wheels explaining the style and depth of the tracks (Fenton, 1918; Parker and Rubinstein, 1984). Zammit, however, was in no doubt that heavy carts with 'solid wooden wheels without a metallic tyre' were used (1928: 18); this has recently been disputed by Ventura and Tanti (1994: 236). 
Gracie (1954), clearly aware that it was unlikely that friction from wooden spars on a slide-car device would produce the tracks, even through soil onto 'soft' rock, suggested that the spars were 'shod' with renewable stone, a solution reiterated and tested by Evans (1959, 1971) and Lewis (1977). No conclusive archaeological evidence has been cited to support this hypothesis.

Function: resource distribution? In the literature, the assumption has been that the incised features represent a transport or communication system that had a purposeful, utilitarian function related to the distribution of particular, or multiple resources over a relatively long time period. It has been conjectured that the network formed:

part of an ancient road system, perhaps one of the oldest extant road systems in the Mediterranean.

Ventura and Tanti, 1994: 236

Speculations on the nature of the resource or resources involved have been strongly influenced as much by the author's own cultural experiences as by the presence or absence of those attributes of the natural environment which might, at any particular point in time, acquire resource value.

The most ubiquitous, accessible, valued resource in the islands is rock. It is not therefore surprising that the tracks have been linked with the transportation of quarried limestone (Abela, 1647; Bonanno, 1994; Lanfranco, 196lb; Parker and Rubinstein, 1984). In contrast, soil - a more basic and essential resource - is far from ubiquitous. The need to redistribute soil, particularly associated with terracing and levelling, continues to transform the contemporary landscape. The origin of this practice, which has persisted for possibly thousands of years in the Maltese Islands, is unknown (Trump, 1993 and pers. comm.). The consequence, in terms of creating and shaping the landscape, is indisputable. The deliberate act of terracing or levelling the scarps, cliffs and ridge-tops on such a huge scale has encouraged speculation that the tracks were used for the distribution of soil from lower to higher areas (Zammit, 1928, 1930; Parker and Rubinstein, 1984; Evans, 1934), or that imported soil was transported along the tracks (Fenton, 1918).

The islands, because of their climate and geology are deficient in surface water, relying (until the advent of desalinization plants) entirely on springs and ingenious strategies for storing the limited, seasonal precipitation. The spatial disassociation of settlements, terraces and springs encouraged Gracie (1954: 95) to suggest that water, carried in animal skins, was transported along the tracks; the asymmetric weight distribution on slopes giving rise to more incised lower tracks as the travois vehicle was pulled along routes that followed the ridges above the spring-line.

The apparent connectivity with coastal sites (Fig. 1) has given rise to the speculation that 'sea products' such as salt, seaweed, and/or fish were transported to settlements on high ground (Trump, 1993: 32), or possible imported/exported agricultural produce (Trump, 1997: pers. comm.). Others have been less specific, suggesting a variety of 'products', possibly including soil but excluding rock, were transported over a long period of time, for different purposes and to different places (Ventura and Tanti, 1994: 236).

Date of the tracks Strong evidence for assigning the tracks to a particular date or period in Maltese history or prehistory does not exist. Conjecture has been based principally on the cross-cutting relationship between tracks and Punic tombs; a perceived spatial association with dated archaeological sites; and a technological 'fix' concomitant with vehicle design.

While there is no consensus, and few maverick suggestions, speculations can be broadly clustered into three groups, either post-dating, contemporaneous with, or pre-dating the late prehistoric, Punic (Late-Phoenician or Carthaginian) phase of occupation around $600 \mathrm{BC}$.

Those who favour a historic date dispute the Punic date for the tombs and attribute the tracks to the Romans (from $218 \mathrm{BC}$ ), perceiving a link between Roman quarries (associated with a distinctive style of rock extraction) and Roman buildings (Lanfranco, 196lb; Bonanno, 1994); attribution to Romans is also suggested where it has been assumed that iron-rimmed wheels and a slave labour traction force were involved (Fenton, 1918).

Ventura and Tanti (1994) consider the tracks could be contemporaneous with the tombs $(c .600$ BC); as new tracks were created, older, abandoned tracks became convenient and accessible sites for locating tombs, thus explaining the cross-cutting relationship. The tracks have been placed 'securely in the later Bronze Age' (Trump, 1993: 33), that is approximately $1500 \mathrm{BC}$, primarily on their perceived association with recorded Bronze Age settlement sites (Trump, 1993; Evans, 1971: 204). Trump's 'loosely fitted heavy carts' (1993: 34) may well have been in use at this time. A similar, but slightly later date (c. $1000 \mathrm{BC}$ ) was also suggested by Gracie (1954) and reiterated by Lewis (1977). Zammit was convinced that the tracks were undoubtedly preRoman and confidently assigned them to the Neolithic Period (Zammit, 1928, 1930), a date supported by Ward-Perkins (1942).

Early writers were predisposed towards more recent, historic dates; attribution to the Arabs (c. 870 $\mathrm{AD})$ was favoured by Abela (1647), while Adams (1870) suggested their origin lay with the Knights (c. $1530 \mathrm{AD})$. 


\section{Discussion}

As ancient networks of incised tracks have not been observed or recorded elsewhere, it is assumed for the moment that the Maltese tracks are an unusual phenomenon. If the network is unique, then it may be an integral component of an exceptional landscape. Despite unequivocal archaeological evidence that the islands had early contact with Sicily and other islands in the central Mediterranean (Trump, 1981; Skeates, 1996; Stoddart et al., 1993), some prehistoric structures that persist in the landscape have been interpreted as singular expressions of ritualization associated with insularity 'unequalled in antiquity' (Stoddart et al., 1993: 4). The bounded and limited resource space of the islands, their geographical isolation, and perhaps some as yet unknown factor or factors, afforded a set of circumstances which gave rise to the cultural divergence which was expressed through elaborate mortuary rituals and temple building; the network of tracks, distinctive in their own right, may be associated with this exceptional period of Maltese prehistory. Archaeologists have argued that this idiosyncratic culture was the result of economic, political and ideological isolation and an expression of a hierarchical society with an increasingly powerful and segregated élite (Renfrew, 1973; Stoddart et al., 1993). The development and organization of an early transport system might also be attributed to the existence of highly centralized political control structures. Alternatively, the existence of an island-wide distribution network may have served to maintain a more egalitarian system which was also expressed and sustained through ritual behaviour.

The tracks represent a purposeful communication network which allowed complementary interaction between different places, in response to a particular human need, at a particular time in Maltese history. The source places and destination places of the network are presently unknown; the nature of the cargo moved about the islands is unknown; the vehicle technology used is unknown; and the time period when this energetic activity occurred in the landscape is unknown; all is conjecture. As the evidence for a convincing consensus is absent, the salient issues, or indeed questions, that have emerged from this review will be addressed briefly pending further analysis.

In contemporary circumstances, complementarity, transferability and intervening opportunities constitute the fundamental bases for spatial interaction (Abler et al., 1972: 193). Applying these basic principles to the ancient tracks, some of the questions that need to be asked are:

- What societal need was satisfied?

- What could be transferred that was not available at destination places and commanded a sufficiently high perceived value to warrant an unusual magnitude and frequency of effort? and
- Were the interactions over relatively long distances because no alternative sources or opportunities existed elsewhere?

If the track system proves to be unique, then a further question must be:

- What environmental and societal factors in these islands afforded the circumstances which gave rise to the impetus and innovation (technological and organizational) which produced such an exceptionally persistent and extensive communication network?

Such questions assume that the spatial behaviour of the society was equivalent to contemporary social behaviour: that it was opportunistic; applied the principle of least effort; and had the technological and social organizational skills to accomplish the task. As there persists in the landscape 'incontrovertible evidence of ritual performance' (Stoddart et al., 1993: 3) associated with cult activity between the fourth and third millennia BC, this particular aspect of human behaviour cannot be ignored as it may have a significant bearing on the spatial strategies that were adopted to sustain the cultural status quo.

The tracks are a persistent record of the purposeful mobilization of some unknown cargo: the resource issue is thus paramount. Cultural perception, appraisal and utilization of spaces, places and material resources, generates spatial processes; the track network is an expression of such a process. A bottom-up approach to explaining the ancient tracks, therefore, demands an understanding of the available resources, and some evaluation of their value to early societies, including how this might have changed in response to environmental and social crises. There has been considerable speculation on the nature of the cargo transported:

- food products (both agricultural and marine);

- materials to facilitate food production (soil, water, seaweed); and

- stone for building or terracing.

There have been hesitant suggestions that external trade might have been involved: the exportation of stone (Abela, 1647); the importation of soils (Fenton, 1918); the import and/or export of food (Trump, 1997: pers. comm.). There are many apparent inconsistencies in the arguments presented:

1 Why if a wetter climate existed would it be necessary to move water all over the islands?

2 Why would rock be moved over hundreds, possibly thousands of metres when it was available locally?

3 Why, if a soil cover existed did soil have to be moved from one place to another, and why build terraces? 
4 If cargo was moved openly across significant distances during the Bronze Age, how does this tally with the massive, landward facing walls constructed around settlements at topographical sites chosen for their defensive advantages?

Many more questions remain to be posed, and answered. The possibility of an 'exotic' cargo connected to cult activities in the islands has not, as yet, been entertained. While material evidence of the cargo may never be discovered, the unusual characteristics and spatial distribution of the tracks, and their association with other archaeological features, may prove to be illuminating.

The morphology and pattern of the network suggest that the activity was either very intensive over a relatively short time period, or persisted at lower intensity over a much longer time period; the implications of any interpretation of the frequency and magnitude of activity is crucial, not only in the context of resources, but in elucidating environmental conditions and social organization.

Initial investigation of the network pattern strongly suggests convergence or divergence at significant nodal sites linked to a primary and secondary distribution system. A general absence of orthogonal tracks; the persistence of parallel and converging tracks at acute angles; the juxtaposition of superimposed tracks; and the existence of loops (possible passing places) suggest a continuity of pattern through time. The persistent pattern or repetition of general routes, suggests a limited period of intensive activity rather than a longer period of less frequent use when a greater diversity of routes might be expected; this will be explored within a GIS environment. Detailed field measurements and analysis of track morphology across the islands are essential to determine the intensity and chronology of use and to establish whether any correlation exists between track parameters, topographical and geological attributes.

A challenging question remains: why are the tracks so incised into the solid rock? The argument that the rock would be sufficiently 'soft' under a covering of soil to be susceptible to superimposed erosion by either wooden wheels, or the stone-clad shafts of a travois, is not entirely convincing. The idea of limestone being 'softer' in a more humid environment may well have been influenced by Houel's original conjecture that the terrain was 'attendri par l'humidité' (1787: 100). There is also an assumption that the bedrock would respond in this manner, and that a relatively thick, obscuring soil cover existed on the upland slopes and plateaux; topographical, geological, pedological and climatic factors tend to nullify this hypothesis.

Climate change, or relatively short-term changes in weather patterns, during the prehistoric period may have triggered phases of accelerated soil erosion
(Hunt, 1997: 108) in an environment already degraded and made vulnerable through human exploitation (Schembri, 1997: 122). Analysis of molluscs from tomb deposits suggests a fairly open landscape existed around 4000 BC (Malone et al., 1995: 342) and pollen analysis indicates very limited tree cover by c.1500 BC (Trump, 1966: 51; Evans, 1971: 24). If a natural, albeit thin, soil cover had existed on the upland limestone, trampling and vehicle movement would have certainly promoted further rapid soil loss. Analysis of sediment cores extracted from lower valleys would help to reveal the chronology of soil erosion events; such data would also be indicative of geological (neotectonic) and climatic perturbations. Similarly, a detailed investigation of micro-karstic weathering phenomena would provide insights into the relative timing of events and might help to explain track discontinuities at the site of solution pits. However, only controlled laboratory experiments to simulate the movement of loaded vehicles across Miocene limestone under variable environmental conditions will produce a totally convincing explanation.

Conjecture on the date of the tracks is based on either their somewhat tenuous chronology with rockcut tombs, or their perceived spatial links with archaeological sites. A particular feature of the Maltese landscape is the physical evidence for the persistent use of particular topographical sites for funereal rituals (Stoddart et al., 1993: 15) and monument building; it is appropriate to regard these as sacred places which acquired and sustained special significance over hundreds, possibly thousands, of years. A consequence of this preferential selection of certain localities is that the archaeological evidence is not always conclusive: rock-cut chambers have frequently been reused, and sometimes remodelled (Evans, 1971; Malone et al., 1995). Artefacts found in tombs, including those cross-cutting tracks, have been attributed to the Punic Period $(c .600 \mathrm{BC})$ indicating usage; tombs of this form - a kidney-shaped chamber leading off a rectangular shaft - have never yielded pre-Punic material (Trump, 1997: pers. comm.). Architectural styles may reflect origin but might also be the result of opportunistic use and elaboration of existing tombs; furthermore, pits or chambers may have been excavated originally for a completely different, non-funereal purpose. Exploring the physical attributes of rock-cut chambers and their spatial relationship with the tracks and other archaeological sites at the island, rather than site-specific scale, may be illuminating.

Throughout the prehistoric period and well into historic times, favoured places remained the focus of concentrated human activity, despite a major cultural discontinuity between 3000 and 2500 BC (Evans, 1959; Trump, 1977). The perceived resource value of these places varied with transitions and 
transformations in culture; cultural shifts are evidenced in the archaeological heritage, through changes in architectural style, artefacts and art.

Ancient tracks have been identified in and around these 'persistent places'. Attribution to late Bronze Age (c. 1500 to $1000 \mathrm{BC}$ ) settlers is supported by a number of authors (Gracie, 1954; Evans, 1971; Trump, 1993) partly because of their geographical link with Bronze Age settlement sites. A conundrum arises because these localities, not necessarily the specific sites, are associated with other cultures: the archaeological spatial 'clusters' may also include Temple Period (4000-3000 BC), Phoenician (675-600 BC) and Roman (218 BC-31 AD) remains. However, Trump (pers. comm., 1997) has pointed out that the Bronze Age period is represented at all such sites. A principal aim of the GIS investigation is to explore the spatial and temporal organization of these 'persistent places' in conjunction with the track network (Hughes, in prep.).

Discontinuous tracks at the edge of coastal and inland cliffs, and those submerged off-shore (Houel, 1787; Adams, 1870; Boisgelin, 1805; Trump, 1993), indicate geological rather than anthropogenic disturbance yet links between geological phenomena and tracks have received scant attention. Chronological links have been suggested with neotectonic activity in Malta and Gozo. Zammit-Maempel (1977), noting the apparent discontinuity and orientation of a pair of tracks on the down-thrown Upper Coralline Limestone at Fomm ir Rih, hinted at their Neolithic origin and a contemporaneous date for movement along the Great (Victoria) Fault system; other geologists have assumed an unspecified Neolithic date for the tracks (Hyde, 1955; Pedley et al., 1976). Evans' (1971: 204) implied attribution to Late Bronze Age immigrants c. $1400 \mathrm{BC}$ was based partly on Gracie's (1954) observation that tracks frequently lead out to promontories, and his contention that such sites were not used for settlement prior to this period. However, it seems likely, considering the susceptibility of the promontory cliffs to excessive erosion and rapid retreat, that much of the archaeological evidence of pre-Bronze Age occupation has been destroyed. Records of temple sites (Trump, 1993: 80; 1981: 136) and megalithic blocks (Trump, 1993: 123 ) close to cliff edges suggest that the assumption of nonoccupation at these localities prior to $1400 \mathrm{BC}$ may be untenable; needless to say, reliable evidence to support such a hypothesis has disappeared.

A more explicit geo-chronological indicator has been found in the Qala region of eastern Gozo (Fig. 1). Reuther, investigating the stress regimes which determined the neotectonic fracture patterns in the sedimentary rocks, identified tracks offset by microfaults. The displacement, associated with feather in feather structures caused by a continuous shearing process in an area still experiencing extension, was assigned, tentatively, to a post-Bronze Age phase of minimal neotectonic activity (Reuther, 1984: 10); this date (around $1000 \mathrm{BC}$ ) can be attributed to Trump's dating of the tracks rather than any absolute geological evidence. Whether geochemical tests on postfracture deposits at this site can assist in dating the displacement of the tracks has yet to be ascertained.

The evidence for Recent, post-Quaternary neotectonic activity is controversial. Pedley has found no convincing evidence of neotectonic displacement of Quaternary deposits, attributing apparent displacements to mass wastage processes (Pedley, 1997: pers. comm.). However, it could be argued that the mass movement of these poorly-consolidated deposits may itself be an indication of superficial instability along existing fault lineaments; evidence in Gozo of continuing extensional processes (Reuther, 1984) lends some support to this suggestion.

Generally, field observations indicate relatively recent geological instability which includes:

1 topographically young, lichen-free, unvegetated and unweathered fault scarps;

2 'fresh' well-polished vertical slickensides;

3 'pop-up' compression structures in eastern Gozo;

4 dislocations of the Pleistocene palaeokarst system (Illies, 1981); and

5 displaced Pleistocene tufa deposits (Hunt, 1997: 102).

Seismic data confirm continuing, albeit generally low magnitude, structural instability (Hyde, 1955; Pedley et al., 1976; Ventura and Galea, 1995).

The frequency, magnitude and variety of mass wastage phenomena have been observed and recorded by a number of authors (Alexander, 1988; Ward-Perkins, 1942; Hobbs, 1914). Field observations, and the lack of correspondence between old maps and the configuration of the present coastline, indicate the rapid rate of contemporary erosion. This can be explained by lithological, climatic and sealevel factors, but accelerated erosion would also be consistent with slight structural instability. Holocene valley deposits (Hunt, 1997: 104-5) testify to periodic sediment fluxes which may have been exaggerated owing to recurrent slope instability.

Post-glacial sea-level changes have certainly been complicated by the geological disposition of the islands. Submerged Quaternary sand dunes, terrestrial fissures, wave-cut platforms, caves and stalagmitic features testify to differential subsidence coupled with a generally transgressing sea; many of the submerged features cluster at around -10 metres, others are found at greater depths (Hobbs, 1914; Pedley et al., 1976; Rizzo, 1932; Hyde, 1955; Martineau, 1965; Trechmann, 1938). Recent data indicate that $c .5000$ years BC, eustatic sea-level was -10metres (Bard et al., 1996: 243); in the case of the Maltese Islands, this 
eustatic sea-level would have been contaminated by a complex neotectonic component.

Features of anthropogenic origin, other than the tracks, are also submerged, including: rock-cut silos, variously attributed to the Bronze Age (Trump, 1993), the Phoenicians (Sinclair, 1924) and the Romans (Ward-Perkins, 1942); the remains of Roman structures and the foundations of early eighteenth-century buildings (Vossmerbäumer, 1972; Sinclair, 1924). This evidence confirms oscillations of the coastline and indicates a relative displacement of at least five to seven metres during the last 2500 to 3000 years. It has been suggested that tectonic movement has occurred during the last 4500 years (Alexander, 1988: 49) as a result of strain-release expressed in 'creeping Holocene movements' (Illies, 1981: 164).

A consequence of sea-level changes and geological instability is that the geometry and physical resource space of the islands differed in the past; this would have had some effect on the perception and behaviour of early occupants, the first of whom may have arrived in the islands around 7000 years BP (Evans, 1971; Trump, 1993; Bonanno, 1994), although it has been suggested that Malta was occupied at a much earlier date (Anati, 1995).

The final issue to be discussed briefly here is the unresolved problem concerning vehicle technology. Essentially, the question hinges on whether wheeled or non-wheeled wooden devices were used along the tracks; in the absence of any physical evidence, the implications of even highly speculative hypotheses are significant. Circular arguments have occurred because of the assumption that wheels were used; this technological 'fix' leads to a chronological 'fix' and a later rather than earlier date for the tracks. Archaeological evidence indicates that the technology and skills associated with the design and construction of wheels for carts was certainly established in Europe by $2500 \mathrm{BC}$ and wheeled sledges existed in Mesopotamia c. 3200 BC (Piggott, 1983: 55). Solid and tripartite wooden wheels have been discovered at various sites in Europe dated to the latter part of the third millennium $B C$, suggesting the rapid transmission and adoption of technology over a few centuries. All these early wheels were small, entirely constructed from wood, with diameters never exceeding 0.9 metre (Piggott, 1983).

Small wheels could not have been responsible for the tracks, as rut-depth, even allowing for post-formation erosion, suggest a high axle vehicle with correspondingly large diameter (over $1.3 \mathrm{~m}$ ) wheels; technological skills to achieve this evolved much later, possibly by the later part of the Bronze Age around 1500 BC (Piggott, 1983). Solid wooden wheels would have been stable and able to withstand the stresses of movement along irregular ruts; larger tripartite wheels, however constructed, would not have survived the mechanical stresses; stone wheels would have disintegrated rapidly. Wood was a scarce resource in the islands (Trump, 1977: 607; Stoddart et al., 1993: 5). Wood or finished wheels, or entire vehicles may have been imported but this seems highly unlikely unless some vital island trade had been established.

If the network evolved at an earlier, pre-Bronze Age date then, with large wheels excluded, the travois device with its simple, robust design might well have been employed. The simple but flexible frame would have required much less wood and no advanced skills; without a fixed axle, the gauge would have varied across the irregular terrain. Traction, if not provided by bullocks, may have been provided by humans braced against a cross-bar near the apex of the frame. Only a relatively small load could be moved leading to a high density of vehicles and frequent journeys. Once initiated, whether by design or by default, ruts would have provided an efficient 'control' system, possibly determining the design of later models. It has been demonstrated that such a device can be moved easily along the tracks (Pike, 1963; Evans, 1971; Lewis, 1977).

\section{Conclusion}

The suggestion that landscape is 'a text on which generations write their recurring obsessions' (Schama, 1995: 12) is exemplified in the landscape of the Maltese Islands. Persistent expressions of obsessiveness are observed in the way prehistoric societies organized or structured their world through architecture, symbolism and mortuary rituals. The archaeological evidence from the fourth millennium $\mathrm{BC}$ reflects a particular cognitive state; a practical, innovative and sophisticated response to a population's need to empower and sustain itself based on its perception, understanding and appraisal of the natural world.

In the Temple Period (c. 4000-3000 BC), the creation of artificial spaces, such as rock-cut and stonebuilt chambers, in deliberately chosen places, and the elaborate, aesthetic and knowledgeable use of local and more exotic geological materials, suggests a cognitive state which emerged through an intense, intimate relationship with the island environment and its natural resources. Through imitation and ritualization, stability, and a perceived measure of reciprocity with the natural world, was sustained over hundreds of years.

Fixed in time and space, the ancient network of tracks may be a persistent 'memory' and adjunct of this sustained, obsessive behaviour. At one level the network simply represents a communication system; a transport rather than ceremonial or symbolic function is assumed at this stage. At another level, the tracks may represent an exaggerated strategic response to a period of unusual stress concomitant 
with a disruptive, possibly catastrophic change in their resource base; biogeographical constraints, environmental fragility, physical isolation and cultural introvertism would have accentuated the impact.

A speculative hypothesis is that the tracks were the result of a strategy adopted in response to an environmental crisis, directly or indirectly related to food procurement, which had a profoundly destabilizing effect on a long-sustained and remarkably sophisticated socio-cultural system. Despite the considerable effort expended, the strategy was ultimately unsuccessful leading to what has been described as the 'sudden and complete' (Trump, 1981: 138) collapse of the Temple Period culture around 3000 BC. This hypothesis will be explored through pattern analysis, spatial correlation and the reconstruction of the palaeo-environment. It will be possible, within a GIS environment, to filter out multiple variables, to reconstruct the resource spaces, and to explore the relationship between landscape and the organization of an island society. However, no assumptions are made and unexpected spatial associations may be discovered which will inform and direct further field research; hopefully, this will contribute towards satisfying Houel's (1787) plea that someone explain the enigmatic Maltese cart-ruts.

\section{REFERENCES}

Abela, G.F. 1647 Della Descrittione di Malta Isola nel Mare Siciliano con le sue Antichità, ed altre Notitie. Malta: Paolo Bonacota.

Abler, R., Adams, J.S. and Gould, P. 1972 Spatial organization: the geographer's view of the world. London: Prentice Hall International.

Adams, A.L. 1870 Notes of a naturalist in the Nile Valley and Malta. Edinburgh: Edmonston and Douglas.

Alexander, D. 1988 A review of the physical geography of Malta and its significance for tectonic geomorphology. Quat. Sci. Rev. 7: 41-53.

Allen, K. et al. (eds) 1990 Interpreting space: GIS and archaeology. London: Taylor and Francis.

Anati, E. 1995 Archaeological exploration in Malta. Bollettino dei Centro Camuno di Studi Preistorici 28: 103-6.

Anati, A.F. and Anati, E. 1988 Missione a Malta. Richerche e studi sulla preistoria dell'archipelago Maltese nel contesto Mediterraneao. Capo di Ponte, Milano: Centro di Studi Preistorici, Jaca Books.

Anderson, E.W. 1997 The wied: a representative Mediterranean landform in Malta. Geojoumal 41(2): 99-114.

Ashby, T., Bradley, R.N., Peet, T.E. and Tagliaferro, N. 1913 Excavations in 1908-1911 in various megalithic buildings in Malta and Gozo. Papers of the British School at Rome 6: $1-126$.

Baldacchino, J.G. and Evans, J.D. 1954 Prehistoric tombs near Zebbug. Papers of the British School at Rome 22(9): 1-21.

Balm, R. 1996 Big holes in a small place. Geography 81(1): 82-91.

Bard, E., Hamelin, B., Arnold, M., Montaggioni, L., Cabioch, G., Faure, G. and Rougerie, F. 1996 Deglacial sea-level record from Tahiti corals and the timing of global meltwater discharge. Nature 382: 241-4.

Blouet, B. 1967 The story of Malta. Valletta, Malta: Progress Press.

Bonanno, A.T. 1994 Archaeology. In Frendo, H. and Friggieri, O. (eds) Malta culture and identity. Valletta, Malta: Ministry of Youth and the Arts: 81-103.

Bonanno, A., Gouder, T., Malone, C. and Stoddart, S. 1990 Monuments in an island society: the Maltese context. Wld Archaeol. 22(2): 190-205.

Boisgelin, L. de 1805 Ancient and modern Malta. London: Richard Philips.

Bosence, D. (ed.) 1990 Field guide to the Cenozoic Platform Carbonates of the Maltese Islands. Field Guide No.22. 13th Int. Sedimentol. Congr. Nottingham, UK 1990.
Bowen-Jones, H., Dewdney, J.C. and Fisher, W.B. 1961 Malta: background for development. Durham: Dept of Geography, University of Durham.

Brea, L.B. 1960 Malta and the Mediterranean. Antiquity 34: 132.

Burgess, G. (ed.) 1997 Gozo Project. archnet@wrwe.lib.uconn.edu. Bristol: Department of Archaeology, Bristol University: Bristol ArchWeb.

Caruana, A.A. 1886 Recent further excavations of the megalithic antiquities of Hagiar-Kim, Malta, executed in the year 1885. Valletta, Malta: Government Printing Office.

-, 1888 Ancient pagan tombs and Christian cemeteries in the island of Malta. Valletta, Malta: Government Printing Office.

Cassar, L.F. 1997 Settlement patterns in the Maltese Islands: from early colonisation to pre-independence, in Malta. Geojournal 41(2): 137-44.

Cherry, J.F. 1981 Pattern and process in the earliest colonisation of the Mediterranean islands. Proc. Prehist. Soc. 47: 41-68.

-, 1990 The first colonisation of the Mediterranean islands: a review of recent research. 7. Medit. Archaeol. 3(2): 145-221.

Chetcuti, D., Buhagiar, A., Schembri, P.J. and Ventura, F. 1992 The climate of the Maltese Islands: a review. Malta: University of Malta, Msida.

Childe, G.V. 1957 The dawn of European civilisation. London: Kegan Paul.

Cooke, J.H. 1896 Notes on the 'Pleistocene Beds' of the Maltese Islands. Geol. Mag. 32: 201-10.

Cope, G.H. (ed.) 1993 British railway track: design, construction and maintenance. Loughborough: The Permanent Way Institution.

Dawkins, W.B. 1918 The Maltese cart-ruts. Man 18: 87-9.

Evans, E.M.P. 1934 Maltese cart-ruts. Antiquity 7: 339-42.

Evans, J.D. 1953 The prehistoric cultural sequence in the Maltese Archipelago. Proc. Prehist. Soc. 19: 41-94.

-, 1959 Malta. In Daniel, G. (ed.) Ancient peoples and places. Series no.11. London: Thames and Hudson.

-, 1971 The prehistoric antiquities of the Maltese Islands. London: Athlone Press.

Farrugia, J. and Briguglio, L. 1996 A focus on Gozo. Malta: University of Malta, Gozo Centre.

Fenton, E.G. 1918 The Maltese cart-ruts. Man 18: 67-72.

Fox, C. 1931 Sleds, carts and wagons. Antiquity 5: 185-99.

Gracie, H.S. 1954 The ancient cart-tracks of Malta. Antiquity 28: $91-8$ 
Guilcher, A. and Paskoff, R. 1975 Remarques sur la géomorphologie littorale de l'archipel Maltais. Bull. de l'Assoc. Géographes Français 427/8: 225-31.

Hobbs, W.H. 1914 The Maltese Islands: a tectonic-topographical study. Scott. Geogrl Mag. 30: 1-13.

Houel, J. 1787 Voyage pittoresque des Iles de Sicile de Malte et de Lipari, où l'on traite des antiquités qui s'y trouvent encore; des principaux phénomènes que la nature y offre; du costume des habitans et de quelques usages. Paris.

Hunt, C.O. 1996 Tafoni (pseudokarst features) in the Maltese Islands. Cave Karst Sci. 23(2): 57-62.

-, 1997 Quaternary deposits in the Maltese Islands. Geojoumal 41(2): 99-114.

Hyde, H.P.T. 1955 Geology of the Maltese Islands. Malta: Lux Press.

Illies, J.H. 1981 Graben formation - the Maltese Islands: a case history. Tectonophysics 73: 151-68.

Jones, A. and Hunt, C. 1994 Walls, wells and water supply: aspects of the cultural landscape of Gozo. Landscape Issues 15: 24-9.

Kraft, J.C., Aschenbrenner, S.E. and Rapp, G.R. 1977 Paleogeographic reconstructions of coastal Aegean archaeological sites. Science 195: 941-7.

Lamb, H.H. 1982 Climate history and the modern world. London: Methuen.

Lambeck, K. 1996 Sea-level change and shore-line evolution: Aegean Greece since the Upper Palaeolithic. Antiquity 70: $588-611$.

Lanfranco, G. 1961a Cynomorium coccineum: a Maltese historical plant. Melita Historica 3: 53-70.

- 1961b The Roman cart ruts of Malta. In Ventura, F. and Tanti, T. 1994 The cart tracks at San Pawl tat-targa, Naxxar. Melita Historica 11(3): 219.

- 1996 The flora and vegetation of Gozo. In Farrugia, J. and Briguglio, L. (eds) A focus on Gozo. Malta: University of Malta Gozo Centre: 26-40.

Lang, D.M. 1961 Soils of Malta and Gozo. In Bowen-Jones, H., Dewdney, H.J.C. and Fisher, W.B. Malta: background for development. Durham: Department of Geography, University of Durham: 83-98.

Lewis, H. 1977 Ancient Malta: a study of its antiquities. Gerrard Cross, Bucks: Colin Smythe.

Llobera, M. 1996 Exploring the topography of mind: GIS, social space and archaeology. Antiquity 70: 612-22.

Lock, G. and Stancic, Z. (eds) 1995 GIS in archaeology: a European perspective. London: Taylor and Francis.

MacArthur, R.H. and Wilson, E.O. 1967 The theory of island biogeography. Princeton: University Press.

Malone, C., Bonanno, A., Gouder, T., Stoddart, S. and Trump, D.1993 The death cults of prehistoric Malta. Sci. Am. 269(6): 76-83.

Malone, C., Stoddart, S. Bonanno, A., Gouder, T. and Trump, D. 1995 Mortuary ritual of 4th millennium BC Malta: the Zebbug Period chambered tomb from Brochtorff Circle at Xaghra (Gozo). Proc. Prehist. Soc. 61: 303-45.

Martineau, M.P. 1965 Marine terraces in Malta. Proc. Symp. Underwater Association for Malta: 69-71.

Mayes, J. 1995 A note on the Winter climate of the Mediterranean: a Maltese case study. 7. Met. 20(203): 323-8.

Mayr, A. 1909 Die Insel Malta im Altertum. Munich: Oskar Beck.

Mitchell, P.K. and Dewdney, J.C. 1961 Climate. In BowenJones, H., Dewdney, J.C. and Fisher, W.B. (eds) Malta: background for development. Durham: Department of Geography: 48-82.
Morris, T.O. 1952 The water resources of Malta. Valletta, Malta: Government Printing Office.

Neumann, J. 1993 Climate changes in Europe and the Near East in the second millennium BC. Clim. Change 23: 231-45.

Newbery, J. 1968 The perched water table in the upper limestone aquifer of Malta. 7. Inst. Wat. Engr 22: 551-70.

Park, C.C. 1977 Dry valley network and density in Malta. Rev. Geomorph. Dynam. 26(2): 49-58.

Parker, R. and Rubinstein, M. 1984 The cart-ruts on Malta and Gozo. Malta: Gozo Press.

Paskoff, R. and Sanlaville, P. 1978 Observations géomorphologiques sur les côtes de l'archipel Maltais. Z. Geomorph. 22(3): 310-28.

Patton, M. 1996 Islands in time: island sociogeography and Mediterranean prehistory. London: Routledge.

Pedley, H.M. 1974 Miocene sea-floor subsidence and later sub-aerial solution subsidence structures in the Maltese Islands. Proc. Geol. Assoc. 85: 533-47.

-, 1980 Sedimentology of Pleistocene Lake Fiddien, near Mtarfa, Malta. Proc. Geol. Assoc. 9(3): 195-202.

Pedley, H.M., House, M.R. and Waugh, B.1976 The geology of Malta and Gozo. Proc. Geol. Assoc. 87: 325-41.

Piggott, S. 1983 The earliest wheeled transport from the Atlantic coast to the Caspian Sea. London: Thames and Hudson.

Pike, G. 1963 Land transport in the Mediterranean in preRoman times. University of London, unpublished MA thesis.

Quintin, J. 1536 The earliest description of Malta (Lyons, 1536). English translation H.C.R. Vella, 1980). Malta: De Bono Enterprises.

Renfrew, A.C. 1973 Before civilisation. London: Cape.

Reuther, C.D. 1984 Tectonics of the Maltese Islands. Centro 1(1): 1-20.

Rizzo, C. 1932 Report on the geology of the Maltese Islands. Valletta, Malta: Government Printing Office.

Schama, S. 1995 Landscape and memory. London: HarperCollins.

Schembri, P.J. 1994 Natural heritage. In Frendo, H. and Friggieri, O. (eds) Malta: culture and identity. Valletta, Malta: Ministry of Youth and the Arts: 105-24.

-, 1997 The Maltese Islands: climate, vegetation and landscape. Geojoumal 41(2): 115-25.

Sinclair, G.G. 1924 Ghar Dalam and the Eurafrican Bridge. 7 . R. Anthrop. Inst. 16: 261-75.

Skeates, R. 1996 Animate objects: a biography of prehistoric 'axe-amulets' in the central Mediterranean region. Proc. Prehist. Soc. 61: 279-301.

Stoddart, S.K.F., Bonanno, A., Gouder, T., Malone, C. and Trump, D.H. 1993 Cult in an island society: prehistoric Malta in the Tarxien period. Cambridge Archaeol. f. 3(1): 3-19.

Tagliaferro, N. 1911 Prehistoric burials in a cave at Bur Meghez near Mqabba, Malta. Man 11: 147.

Trechmann, C.T. 1938 Quaternary conditions in Malta. Geol. Mag. 75: 1-26.

Trump, D.H. 1962 Origin of the Maltese temples. Antiquity 36: 59.

-, 1963 Carbon, Malta and the Mediterranean. Antiquity 37: 302-3.

-, 1966 Skorba. Oxford: Research Report of the Society of Antiquaries of London 22.

-, 1977 The collapse of the Maltese temples. In Sieveking, G. De G., Longworth, I.H. and Wilson, K.E. (eds) Problems in economic and social archaeology. London: Duckworth: 605-10.

-, 1981 Megalithic architecture in Malta. In Evans, J.D., 
Cunliffe, B. and Renfrew, C. (eds) Antiquity and man: essays in honour of Glyn Daniel. London: Thames and Hudson: 128-40.

-, 1993 Malta: an archaeological guide. Valletta, Malta: Progress Press

Ugolini, L.M. 1934 Malta: origine della civiltà Mediterranea. Rome: Libreria dello Stato.

Van Andel, T.H. 1989 Late Quaternary sea-level changes and archaeology. Antiquity 63: 733-46.

Vance, J.G. 1842 Ancient temple near Crendi, Malta. Archaeologia 29: 227-40.

Ventura, F. and Galea, P. 1995 The 1693 earthquake in the context of seismic activity in the central Mediterranean region. In Azzopardi, J. (ed.) Mdina and the earthquake of 1693. Malta: Heritage Books: 5-23.

Ventura, F. and Tanti, T. 1994 The cart tracks at San Pawl tat-targa, Naxxar. Melita Historica 11(3): 219-40.

Vossmerbäumer, H. 1972 Malta, ein Beitrag zur Geologie und Geomorphologie des Zentralmediterranen Raumes. Wurzburger Geograph. Arbeit. 38: 1-213.
Ward-Perkins, J.B. 1942 Problems of Maltese prehistory. Antiquity 16: 19-35.

Weiss, B. 1982 The decline of Late Bronze Age civilization as a possible response to climatic change. Clim. Change 4: 173-98.

Whitehouse, R. 1972 The rock-cut tombs of the central Mediterranean. Antiquity 46: 275-81.

Zammit, T. 1928 Prehistoric cart-tracks in Malta. Antiquity 2: 18-25.

-, 1930a Prehistoric Malta: the Tarxien temples. Oxford: O.U.P.

-, 1930b The prehistoric remains of the Maltese Islands. Antiquity 4(13): 55-79.

-, 1935 The Neolithic hypogeum at Hal Saftieni at Casal Paula, Malta. Malta.

Zammit-Maempel, G. 1977 An outline of Maltese geology and guide to the Geology Hall of the National Museum of Natural History Mdina, Malta. Valletta. Malta: Progress Press.

Zubrow, E.B.W. 1994 Knowledge representation and archaeology: a cognitive example using GIS. In Renfrew, C. and Zubrow, E.B.W. (eds) The ancient mind: elements of cognitive archaeology. Cambridge: C.U.P.: 107-18. 